\title{
Escape from $X$ Chromosome Inactivation and the Female Predominance in Autoimmune Diseases
}

\author{
Ali Youness ${ }^{1,+}$, Charles-Henry Miquel ${ }^{1,2,+}$ and Jean-Charles Guéry ${ }^{1, *(D)}$ \\ 1 Infinity-Toulouse Institute for Infectious and Inflammatory Diseases, University of Toulouse, INSERM, CNRS, \\ UPS, 31300 Toulouse, France; Ali.youness@inserm.fr (A.Y.); charles-henry.miquel@inserm.fr (C.-H.M.) \\ 2 Arthritis R\&D, 92200 Neuilly-Sur-Seine, France \\ * Correspondence: jean-charles.guery@inserm.fr; Tel.: +33-5-62-74-83-78; Fax: +33-5-62-74-45-58 \\ + These authors contributed equally to this work.
}

Citation: Youness, A.; Miquel, C.-H.;

Guéry, J.-C. Escape from X

Chromosome Inactivation and the

Female Predominance in

Autoimmune Diseases. Int. J. Mol. Sci.

2021, 22, 1114. https://doi.org/

10.3390/ijms22031114

Academic Editor: Antoine Martinez

Received: 30 December 2020

Accepted: 19 January 2021

Published: 23 January 2021

Publisher's Note: MDPI stays neutral with regard to jurisdictional claims in published maps and institutional affiliations.

Copyright: (C) 2021 by the authors. Licensee MDPI, Basel, Switzerland. This article is an open access article distributed under the terms and conditions of the Creative Commons Attribution (CC BY) license (https:// creativecommons.org/licenses/by/ $4.0 /)$

\begin{abstract}
Women represent $80 \%$ of people affected by autoimmune diseases. Although, many studies have demonstrated a role for sex hormone receptor signaling, particularly estrogens, in the direct regulation of innate and adaptive components of the immune system, recent data suggest that female sex hormones are not the only cause of the female predisposition to autoimmunity. Besides sex steroid hormones, growing evidence points towards the role of X-linked genetic factors. In female mammals, one of the two $\mathrm{X}$ chromosomes is randomly inactivated during embryonic development, resulting in a cellular mosaicism, where about one-half of the cells in a given tissue express either the maternal $X$ chromosome or the paternal one. $\mathrm{X}$ chromosome inactivation $(\mathrm{XCI})$ is however not complete and 15 to $23 \%$ of genes from the inactive $\mathrm{X}$ chromosome $(\mathrm{Xi})$ escape $\mathrm{XCI}$, thereby contributing to the emergence of a female-specific heterogeneous population of cells with bi-allelic expression of some X-linked genes. Although the direct contribution of this genetic mechanism in the female susceptibility to autoimmunity still remains to be established, the cellular mosaicism resulting from XCI escape is likely to create a unique functional plasticity within female immune cells. Here, we review recent findings identifying key immune related genes that escape XCI and the relationship between gene dosage imbalance and functional responsiveness in female cells.
\end{abstract}

Keywords: autoimmune diseases; sex bias; systemic lupus erythematosus; $\mathrm{X}$ chromosome inactivation

\section{Introduction}

In general, women have stronger immune systems than men, they also suffer more from autoimmunity and subsequent inflammation-induced tissue damage. Although the influence of environmental factors acting on genetically predisposed individuals is an important element contributing to the development of autoimmunity, emerging evidence indicates that X-linked genetic factors and sex hormone signaling may act in concert to trigger the sex-specific development of these immunological disorders [1]. Indeed, autoimmune diseases affect women and men differently. In an industrialized country, about $5 \%$ of the population suffers from autoimmune diseases, which is estimated to represent between 14 to 23 million people in the United States [2], of which women are the most affected category (70 to $80 \%$ ). This is the case with scleroderma, rheumatoid arthritis (RA), multiple sclerosis (MS), systemic lupus erythematosus (SLE), Sjögren's syndrome, which are three to seven times more common in women than men [3].

The enhanced susceptibility of women to autoimmunity correlate with the observations that women develop faster immune responses, with higher amplitude and of better quality, compared to men to various types of pathogens and vaccines [4]. Women have also higher levels of circulating antibodies, more CD4 T cells and B cells in their blood, develop more robust cytokine responses to infection, and enhanced rejection of tumors and allografts [5]. An increased immunity in females is well conserved in mammals [6]. Because of strong immune responses female experience fitness benefits of immunity, such 
as accelerated clearance of infection to promote survival or provision of maternal antibodies to protect offspring from lethal infection, but are also likely to suffer its costs. Although the enhanced female predominance of autoimmune diseases has come up only recently due to the increase in life expectancy and the environmental changes in developed countries associated with the decline in infectious disease prevalence [7].

The female bias in autoimmune diseases was initially mainly attributed to the female sex hormones, estrogens, yet female predominance in autoimmune diseases is frequently observed in childhood or in postmenopausal women when estrogen levels are low [3]. More recently sex chromosomes have been put forward as a genetic mechanism to explain the sex-differences in immune responses over a wide-range of age $[1,8]$. Understanding the genetic mechanisms by which sex chromosomes, particularly the $\mathrm{X}$ chromosome, contribute to influence the strength and magnitude of immunity may, therefore, have implications, not only for the treatment of these immunopathological disorders, but also for promoting optimal protective immunity in response to pathogens or for improving vaccine efficacy.

\section{The Role of X Chromosome in Sex Bias in Autoimmune Diseases}

In most eukaryotic species, the sex of the individual is determined from the heteromorphic sex chromosome pairs. The female mammals have $2 \mathrm{X}$ chromosomes (homogametic) while the male is heterogametic with $1 \mathrm{X}$ chromosome and $1 \mathrm{Y}$ chromosome forming the pair of sex chromosomes (Figure 1). The $Y$ chromosome is a small $59 \mathrm{Mb}$ chromosome compared to the $154 \mathrm{Mb}$ of the $\mathrm{X}$ chromosome which encodes more than 1000 genes (Figure 2). The chromosome Y contains a 'male-determining gene', the SRY gene. The presence of Sry in mice determines the development of the testes, and the consequent production of testosterone. In the absence of a functional Sry gene, the default pathway leads to the development of female-like embryos with ovaries. A transgenic mouse model, known as four core genotypes (FCG) was used to investigate the impact of sex chromosomes, regardless of the presence of male or female hormones, on the development of autoimmune disease. The deletion of Y-linked gene (Sry) in male mice (Y Sry-), prevented the development of testis resulting in mice with a female-like hormonal background similar to that of XX mice. Backcrossing these females with males expressing a Sry transgene on an autosome results in Syr+ XX or XY animals with testes. Mice carrying the XX sex chromosome complement developed increased susceptibility to lupus syndrome, compared to $X Y$ mice, regardless of the male or female hormonal environment. This model thus reveals the impact of sex chromosomes on susceptibility to the disease in a context of identical gonadal sex. In humans, the role of the $\mathrm{X}$ chromosome has been revealed in males with Klinefelter's syndrome $(X X Y)[9,10]$. These men who carry one or more extra $X$ chromosomes have an equivalent risk to women of developing lupus or Sjögren's syndrome [11,12]. These data suggest that the $\mathrm{X}$ chromosome number plays a role in the susceptibility for developing autoimmune diseases in a genetically predisposed environment. These observations led to the hypothesis that candidate genes on the inactive $\mathrm{X}$ chromosome could potentially contribute to the development of autoimmunity, in particular SLE and Sjögren syndrome. However, although the strength of the FCG model allows to distinguish the effects of sex chromosomes from those of sex hormones, one of its limitations is the inability to differentiate between the addition of an inactive $\mathrm{X}$ chromosome $(\mathrm{Xi})$ or the loss of a $\mathrm{Y}$ chromosome. 
A

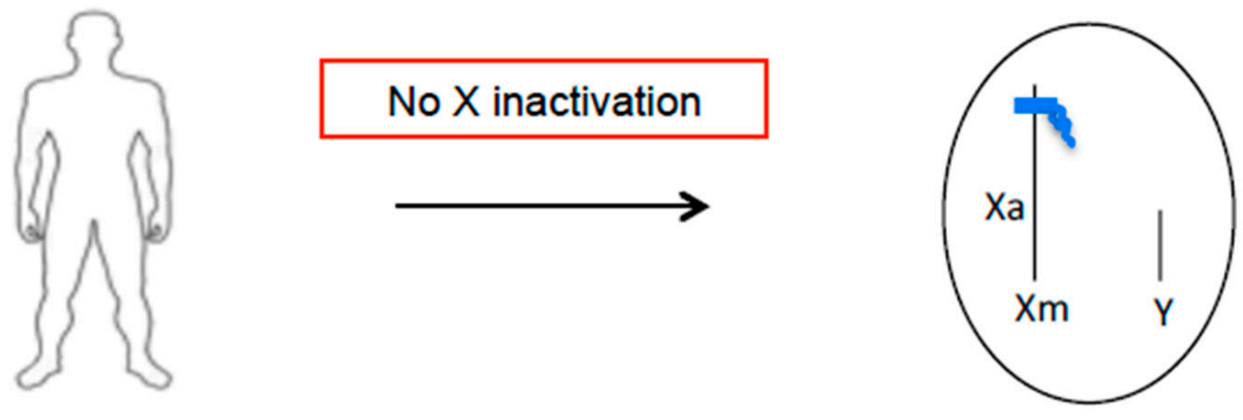

B

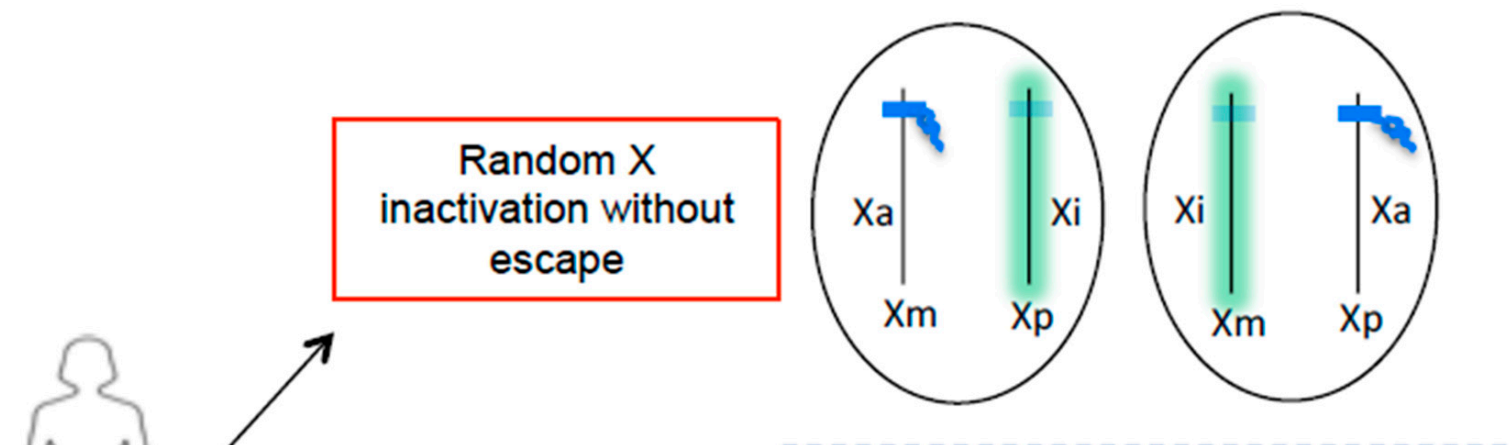

C
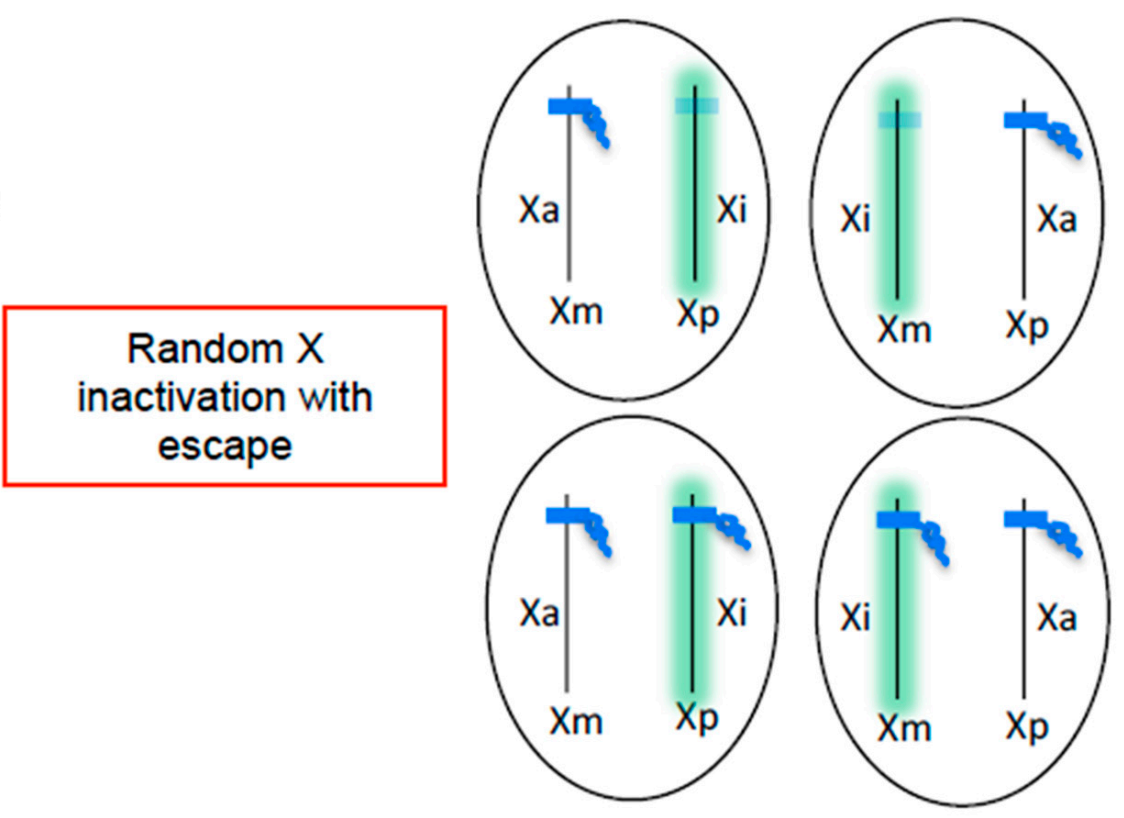

Figure 1. $X$ chromosome inactivation escape generates additional cellular heterogeneity in the expression of $X$-linked genes in women. Men have only one active X chromosome (A) and women have two X chromosomes inherited from each parent (maternal $X=X m$, paternal $X=X p$ ). In order to balance the dosage of genes carried by the $X$ chromosome between males and females, one of the two chromosomes $X$ is randomly inactivated during embryonic development in women (B,C). This process is initiated by the long non-coding RNA XIST (green), which becomes highly expressed on one allele and coats the future inactive $\mathrm{X}$ chromosome $(\mathrm{Xi})$ in cis, leading to transcriptional repression. The result is a cell mosaic where in theory half of the cells have an active chromosome (Xa) of maternal origin and the other half of paternal origin (B). However, certain genes can escape $\mathrm{XCI}$, including $T L R 7$, generating additional cellular heterogeneity in the expression of $\mathrm{X}$-linked genes (C). 


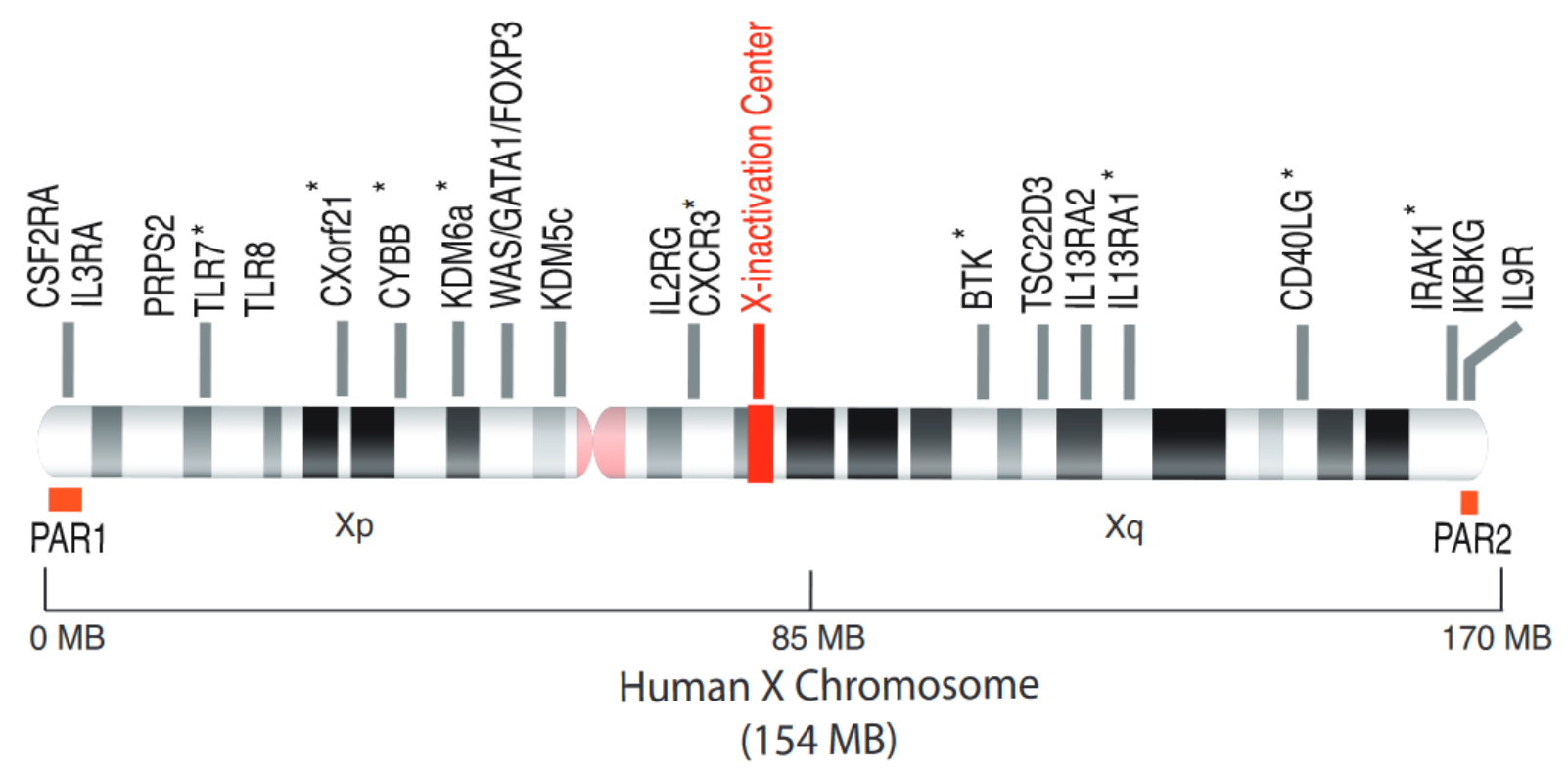

Figure 2. The human $X$ chromosome and the escapee genes from $X C I$. The human $X$ chromosome, 154 MB in size, codes for around 1100 genes, many of which are involved in immune responses (WAS, BTK, FOXP3, IL2RG). The TLR7 gene, located on the short arm of the X chromosome, is able to escape from XCI. The other genes whose escape has been clearly demonstrated, are annotated with an asterisk $\left(^{*}\right)$ and described in the Table 1. PAR1, pseudoautosamal region 1; PAR2, pseudoautosomal region 2 .

\section{Candidate X-Linked Genes Escaping from XCI with Possible Contribution in Autoimmune Diseases}

Due to the imbalance of $X$ chromosome between females $(X X)$ and males $(X Y)$, regulation of $\mathrm{X}$-linked gene dosage is strictly necessary. Abnormal increase in $\mathrm{X}$-linked gene expression due to the presence of the extra $\mathrm{X}$ chromosome in females leads to developmental dysfunction [13]. Therefore, in female mammals, one of the two X chromosomes is randomly inactivated, in the early embryo, to balance the dosage of gene expression between the sexes. The process of X chromosome inactivation (XCI) results in cellular mosaicism (Figure 1), where about half of the cells in a tissue express genes from the maternal X chromosome and the other half from the paternal X chromosome [13]. However, the pseudo-autosomal regions (PAR) of the $\mathrm{X}$ chromosome, PAR1 and PAR2, do not undergo XCI (Figure 2). These regions carry a minority of X-linked genes with functional homologues on the $\mathrm{Y}$ chromosome, and these genes (e.g., CSF2RA, SLC25A6 and IL3RA on PAR1 or IL9R on PAR2). Indeed, these telomeric regions are the only part sex chromosomes that can recombine in male meiosis [14]. Most of the genes outside the pseudo-autosomal regions, however, are unique to the $\mathrm{X}$ chromosome with two copies in women and only one in men. Most of these genes encode proteins and microRNAs known to directly or indirectly regulate the immune response $[8,15,16]$. Loss-of-function mutations in some of these genes (e.g., BTK, WAS, IL2RG, FOXP3) cause primary X-linked immune deficiencies [8]. The $X$ chromosome is known to contain the largest number of immune-related genes of the whole human genome (Figure 2). The endosomal Toll-like receptor (TLR) genes, TLR7 and TLR8, of the non-pseudo-autosomal region of $\mathrm{Xp}$, attest to non-redundant vital functions [17]. In support of the key role of TLR7 in certain infections, a recent study has identified loss-of-function mutations of TLR7 associated with severe forms of COVID-19 in young men, suggesting a key role of TLR7 in the protective response against SARS-CoV2 [18]. However, XCI is incomplete and 15-23\% of human X-linked genes escape XCI (Figure 1), and are thus overexpressed from both the active (Xa) and inactive $(\mathrm{Xi}) \mathrm{X}$ chromosome in certain tissues or individuals $[19,20]$.

The $X$ chromosome has recently been the subject of numerous studies aimed at understanding the role of genes on the $\mathrm{X}$ chromosome in the initiation and maintenance of 
autoimmune aggression. Therefore, it is interesting to discuss how certain X-linked genes might become overexpressed in female autoimmunity and the functional consequences associated with cell-intrinsic imbalance in X-linked gene expression. These genes are listed in Table 1.

Table 1. Genes that escape from XCI in immune cells.

\begin{tabular}{|c|c|c|c|}
\hline Gene Symbol & Gene Nomenclature & Cell Type & Reference \\
\hline IRAK1 & interleukin 1 receptor associated kinase & $\begin{array}{l}\text { variable escapes in primary fibroblast cell } \\
\text { lines }\end{array}$ & [19] \\
\hline CD40LG & CD40 ligand & \multirow{2}{*}{$\begin{array}{l}\text { escape in activated T cells and } \\
\text { immortalized B-cell lines generated from } \\
\text { pediatric SLE patients or healthy females }\end{array}$} & \multirow{2}{*}{ [21] } \\
\hline CXCR3 & C-X-C motif chemokine receptor 3 & & \\
\hline IL13RA1 & interleukin 13 receptor subunit alpha 1 & \multirow{2}{*}{ escape in pDC from healthy women } & \multirow{2}{*}[22]{} \\
\hline$C Y B B$ & cytochrome b-245 beta chain & & \\
\hline \multirow[t]{2}{*}{ TLR7 } & \multirow[t]{2}{*}{ toll like receptor 7} & $\begin{array}{l}\text { escapes in monocyte, lymphocyte B and } \\
\text { pDC from healthy women and Klinefelter } \\
\text { syndrome males (XXY) }\end{array}$ & [23] \\
\hline & & escapes in pDC from healthy women & [22] \\
\hline KDM6a & lysine demethylase $6 \mathrm{~A}$ & $\begin{array}{l}\text { escapes in mouse-human somatic } \\
\text { cell hybrids }\end{array}$ & [24] \\
\hline BTK & Burton tyrosine kinase & escapes in pDC from healthy women & [22] \\
\hline CXorf21/TASL & $\begin{array}{c}\text { chromosome } \mathrm{X} \text { open reading frame 21; } \\
\text { also known as TASL (TLR adaptor } \\
\text { interacting with SLC15A4 on the } \\
\text { Lysosome) [25] }\end{array}$ & $\begin{array}{l}\text { variable escapes in primary fibroblast } \\
\text { cell lines }\end{array}$ & [19] \\
\hline
\end{tabular}

\subsection{The Intracellular ssRNA Sensors: TLR7 and TLR8}

The involvement of Toll-like Receptors (TLR) in the recognition of self-molecules is established for the RNA-sensing receptors of innate immunity, TLR7 and TLR8, which enhanced expression is directly linked to the pathogenesis of autoimmune diseases [1,26]. Although closely located on the X-chromosome, the regulation of TLR7 and TLR8 expression is strikingly different as both receptors are not present on the same cell types and are not regulated equally by cytokines. TLR7 is expressed primarily in plasmacytoid dendritic cells ( $\mathrm{pDC}$ ), B lymphocytes and monocytes but TLR8 is preferentially expressed in monocytes, myeloid dendritic cells and neutrophils. Activation of TLR7 in monocytes preferentially promoted the expression of CD4+ T helper 17 (Th17) cell polarizing cytokines after virus infection, whereas Th1-type cytokine production and type I interferon response were dependent on TLR8 signaling [27]. Both TLR8 and TLR7 could contribute to the pathogenesis of autoimmune diseases. TLR8 is a key player in the pathogenesis of systemic Sclerosis (SSc) due to its aberrant expression in pDCs from SSc patients and its ability to exacerbate disease in mouse model of scleroderma [28]. Several studies have shown that the expression of two copies of Tlr7 or Tlr8 alone was sufficient to induce autoimmunity in mice [29-31], whereas mice deficient in $T l r 7$ with a genetic background predisposing to lupus are significantly protected against autoimmunity [32]. TLR7 plays a key role in the B response in lupus, the production of anti-ribonucleoprotein (RNP) autoantibodies, as well as in the production of type I IFN (IFN-I) by pDCs [33]. We have shown that TLR7 escapes from XCI in pDCs, B cells and monocytes from females, as well as from Klinefelter's males $(47, \mathrm{XXY})$ [23]. In addition to cells exhibiting, as expected, a mono-allelic expression of the gene carried by the $X$ of paternal or maternal origin, we detected in all subjects, a proportion of cells exhibiting biallelic expression of TLR7 with frequencies ranging from 7 to $45 \%$ depending on the subjects. Female B cells with escape from XCI of TLR7 had higher TLR7 mRNA levels compared to B cells with mono-allelic expression of the gene. 
Remarkably, TLR7 protein expression was higher in women blood leukocytes compared to men [23], and this enhanced expression of TLR7 protein in women PBMCs was maintained over ages [34]. B cell from women stimulated through TLR7 in vitro differentiated more efficiently into CD27hi plasmablasts than B cells from men, and were enriched in cells with biallelic expression of TLR7 [23]. Likewise, a positive association was also observed between TLR7 biallelism and IgG class switching of naive B cells exposed to TLR7 agonists but not upon addition of agonists for TLR9 located on chromosome 3 [23]. Together, these results suggested a functional advantage of $T L R 7$ biallelic $B$ lymphocytes at various check-point of B cell responses in response to TLR7-specific ligands [1,26].

Recently, using a single-cell RT-PCR approach to tag allelic expression of TLR7 using SNP markers similar as the one described in [23], Hagen et al. [22] confirmed that TLR7 escapes from XCI, leading to biallelic expression patterns in human pDCs. Biallelic expression of TLR7 had significantly higher TLR7 mRNA transcript levels than female monoallelic-TLR7-expressing pDCs. IFN $\alpha$ and IFN $\beta$ mRNAs were more highly transcribed in female unstimulated pDCs with biallelic expression of TLR7, suggesting a causal link between escape of TLR7 from XCI and higher induction of type I IFN mRNA in these pDCs [22]. Of note, in the same study bi-allelic expression of other X-linked genes (e.g., RPS6KA3, CYBB, BTK, IL13RA1) was also observed in female pDCs. Simultaneous examination of up to 3 different loci withing the same cells showed heterogenous profile of $\mathrm{XCI}$ escape at single-cell resolution suggested that XCI escape at multiple loci was a rare event [22].

Tlr8, like Tlr7, escapes from $\mathrm{XCI}$ in mice, but the functional consequences are not known [26]. In human, this raised the question whether TLR8, like TLR7, may also escape from XCI in female cells.

\subsection{The IRF-5 Adaptor Molecule CXorf21/TASL.}

The function of this gene has been recently characterized, and CXorf21 has been renamed as "TLR adapter interacting with the SLC15A4 on the lysosome" (TASL) [25]. TASL interacts with the endolysosomal transporter SLC15A4 to activate the IRF-5 pathway following the engagement of endosomal TLR receptors (TLR7, 8 and 9). TASL shares functional homology with the adapter proteins STING, MAVS and TRIF and appears to be a central "hub" in the activation of the TLR-IRF5 pathway [25]. It has been suggested that CXorf21/TASL, which is an interferon inducible gene, has been predicted to be subject to XCI escape, although this has not been formally established yet [35]. Additionally, a genetic polymorphism in the Xp21.2 region in the exon encoding the CXorf21 gene has been shown to be strongly associated with SLE in European populations and CXorf21 mRNA expression levels in peripheral blood cells are indicators of SLE flares [36,37]. Taken together, these observations suggest that CXorf21/TASL is a strong candidate gene in SLE, for which enhanced dosage in female immune cells due to XCI escape may contribute to the gender bias observed in some autoimmune diseases such as SLE.

\subsection{Immune Cell Homing and Third Signal Delivery: CXCR3 and CD40L}

CXCR3 and CD40LG are encoded by genes on the X chromosome and are both subject to XCI escape in immune cells [21]. Biallelic expression of CXCR3 and CD40LG has been documented in $\mathrm{T}$ cells and lymphoblastoid $\mathrm{B}$ cells, respectively, with frequencies ranging from 4 to $5 \%$, using single-cell RNA FISH analysis [21]. XCI escape of CXCR3 has been elegantly confirmed in a dual reporter mouse model [38]. Female T cells with bi-allelic expression of CXCR3 from both X chromosomes had higher CXCR3 protein levels than monoallelic cells and showed functional differences compared to mono-allelic cells, in a model of L. mexicana infection [38].

CD40LG is a T-cell coactivation receptor, which activate B cells and DCs through CD40 engagement, and is expressed under transcriptional control of nuclear factor of activated T-cells (NFAT). A recent study showed that a duplication of CD40L was associated with autoimmune manifestations, increased expression of CD40L and the functional ability of T 
cells to promote B cell activation and differentiation in vitro [39]. As reported for TLR7 in human B cells [23] and pDCs [22], it is likely that the escape from XCI of CXCR3 or CD40L may have functional consequences for sex-specific immune functions $[38,39]$.

\subsection{The Histone Demethylase KDM6a (Lysine Demethylase 6A, also Known as Utx)}

$K D M 6 a$ escapes from $X$ chromosome inactivation [24], potentially leading to higher expression of KDM6A in immune cells of females as compared with males, in human and mouse [40]. It is involved with KMT2D in the activation of gene expression by modifications of histones which makes chromatin permissive for transcription. KDM6a removes the repressive marks associated with the triple methylation of lysine 27 of histone H3 (H3K27me3) then it associates with the methyltransferase KMT2D which can add the activating marks on lysine 4 of histone $\mathrm{H} 3$ (H3K4me3) [40]. The role of Kdm6a in autoimmunity has been recently illustrated in experimental autoimmune encephalomyelitis (EAE), the mouse model of multiple sclerosis (MS). The deletion of $K d m 6 a$ in mouse CD4 ${ }^{+}$ $\mathrm{T}$ cells diminished neuroinflammation and protected mice from MS-like symptoms in the EAE model, due to a defect in the differentiation of pathogenic T lymphocytes [41]. This observation could explain the protective effect of the diabetes drug metformin, which is known to block the demethylase activity of KDM6a. Since Kdm6a/Utx expression in CD4 ${ }^{+} \mathrm{T}$ cells promotes disease in EAE, escape from XCI and overexpression of $\mathrm{Kdm} 6 \mathrm{a}$ in females is consistent with the increased susceptibility of women to multiple sclerosis [41]. However, $K D M 6 A$ escape is not all bad news for women health as this gene is also a tumor suppressor. The rate of cancer in men is more than double that in women, and KDMA6A mutation are more common in men's cancer than in women's [42]. Scanning cancer mutations in various tumor types for genes exhibiting more mutations in men than in women led to the characterization of six genes implicated as tumor suppressors, all on the $\mathrm{X}$ chromosome, including KDM6A [42]. Because all these $\mathrm{X}$-linked genes were reported to escape XCI, these results supported the idea that expressing spare tumor suppressors from the $\mathrm{Xi}$ may contribute to avoid cancer in women, as females would require two deleterious mutations to inactivate the genes. By contrast in men, with only one $X$, a single mutation in those genes may be sufficient to substantially contribute to the observed higher incidence of cancer in males across a variety of tumor types [42].

\section{Role of XIST RNA Localization on the Xi in AID?}

$\mathrm{XCI}$ is dependent on epigenetic features including the transcription of the long noncoding RNAs (lncRNA), XIST, encoded by an X-linked gene, on the future inactive $\mathrm{X}$ chromosome ( $\mathrm{Xi})$, which accumulates along this chromosome in cis [13]. This event initiates the silencing of X-linked genes by recruiting the polycomb repressive complex 1 (PRC1) and 2 (PRC2) which are responsible for mono-ubiquitylation of lysin 119 on the histone $\mathrm{H} 2 \mathrm{~A}$ (H2AK119ub1) and trimethylation of the lysine 27 on histone H3 (H3K27me3) on the $\mathrm{Xi}$. The acquisition of these epigenetic features is involved in the stable maintenance of the inactive state [13]. Although the role of Xist in the initiation of XCI is well established; its function in XCI maintenance is debated and still unclear. Actually, earlier works have reported that global and efficient XCI can be maintained in the absence of XIST in mature differentiated cells [43,44].

Analysis of the $X_{i}$ in lymphoid cells have shown that the presence of Xist RNA and H3K27me3 were present on the Xi in HSCs and CLPs, whereas these marks were absent in pre-B, and immature B cells [45]. Chromatin of the $\mathrm{Xi}$ progressively changes during B cell development, initiated with the loss of Xist RNA, and heterochromatin marks gradually disappear from the $\mathrm{X} i$ as pro-B cells differentiate to immature $\mathrm{B}$ cells $[45,46]$. B lymphocytes lack these marks at steady state and exhibit a unique dynamic localization of these modifications to the $\mathrm{Xi}$ following activation. Loss of these marks on the $\mathrm{Xi}$ at steady state was transient, and XIST RNA relocalization together with H3K27me3 and H2AK119ub1 occurred at the $\mathrm{Xi}$ upon transition from quiescence to activation [21,46]. In particular, it was shown that, upon B cell activation, the XIST RNA localization to the Xi 
was restored in a dynamic two-step process involving the transcription factor YY1 [46]. Similar observation was made in T cells [47]. Xist RNA localization at the $\mathrm{Xi}$ was altered in activated T cells of SLE patients and late-stage-disease NZB/NZW F1 mice, suggesting that $X i s t$ localization to the $X i$ could contribute to the maintenance of dosage compensation in lymphoïdes cells [47]. However, the overall significance of Xist repositioning to the $\mathrm{Xi}$ in activated lymphocytes compared to naïve cells remain to be addressed.

It was hypothesized that some genes on the inactive $\mathrm{X}$ chromosome $(\mathrm{Xi})$ are predisposed to become partially reactivated in the naïve female lymphocytes [21]. However, examination of allelic expression of putative disease-causing candidate genes like $T l r 7$ failed to reveal major differences in biallelic cell frequencies between B cells from lupusprone and wild-type mice [48]. Although the number of subjects was too low to draw any conclusions, no marked differences in TLR7 biallelic cell frequencies was also observed in EBV-B cells between SLE sufferers and healthy women [21]. In a recent study, conditional deletion of Xist in neurons was associated with lack of expression of the repressive marks (H2AK119ub1, H3K27me3) on the Xi. Despite this, XCI was largely preserved in the vast majority of the cells, suggesting that the maintenance of transcriptional repression of the $\mathrm{Xi}$ is largely independent of Xist at least in neurons [49].

Whether Xist RNA relocalization to the $\mathrm{X} i$ in activated $\mathrm{T}$ and $\mathrm{B}$ cells affect the expression of genes on the $\mathrm{Xi}$ remains to be established.

\section{Interactions between Sex and Genetic Polymorphism: the Case of the rs179008 Polymorphism of TLR7}

The effect of genotypes may be different between males and females due to certain genetic polymorphisms, or expression quantitative trait loci (eQTL), responsible for sexspecific genetic architecture [50]. The TLR7 polymorphism rs179008 (NM_016562.3:c.32A>T) has been recently identified as a sex-specific eQTL, causing a difference in functional expression of TLR7 protein and effector function only in females [34]. The rs179008 is a SNP which introduces a substitution of a leucine for a glutamine (p.Gln11Leu) at the protein level in the leader sequence of TLR7 thereby controlling protein dosage at the translational level through the mRNA sequence itself, rather than through signal peptide function [34]. The minor allele rs $179008 \mathrm{~T}$ impaired type I interferon production by pDCs in response to TLR7 ligands, but only in women. Thus, the sex bias in pDC function mirrored a genotype-dependent drop in TLR7 protein expression in female leukocytes, consistent with the notion that TLR7 dosage in pDCs determines type I interferon secretion [22,51]. Importantly, in a cohort of acute HIV-1 infected women, rs179008 T allele was significantly associated with lower levels of a triad of positively correlated parameters: RNA viral load, the cell-associated HIV-1 DNA reservoir, and plasma IP-10. In addition, the higher frequency of asymptomatic clinical presentations at diagnosis for the $\mathrm{T} / \mathrm{T}$ homozygous genotype implies a trend for a delayed onset of the symptoms of acute infection, supporting a beneficial effect of toning down TLR7-driven IFN-I production by pDCs during acute HIV-1 infection [34]. Beside its potential effect in viral infections the rs179008 SNP has been also associated with the susceptibility to SLE [52]. By increasing the susceptibility of women to certain viral infections, such SNP could have deleterious consequences as failure to control viral infections has been associated with the onset of SLE [53,54].

\section{Conclusions}

Sex hormones play an indisputable role in the greater susceptibility of women to develop autoimmune diseases. More recently, it has been shown that in addition to sex hormones, X-linked genetic factors contribute to the functional plasticity of immune cells in females, suggesting that epigenetic mechanisms regulating the inactive $X$ chromosome may have important implication in the enhanced female susceptibility to autoimmune diseases. However, sex chromosome and sex hormone effects cannot be regarded as totally independent. For instance, considering the nucleic acid sensor axis TLR7/9-IRF5-TASL, evidence exist suggesting a concerted action of sex hormones and $\mathrm{X}$ chromosome complement in TLR7-driven pDC interferogenesis [51]. One can speculate that sex hormones 
and sex chromosomes may independently control the protein levels of key components of the upstream and downstream signaling modules of the endosomal TLR pathway, with estrogen-signaling regulating IRF5 mRNA expression levels whereas $\mathrm{X}$-linked genetic mechanisms controlling expression of TLR7 though XCI escape and gene dosage effects $[22,23,55]$. Regarding the causal relationship between XCI escape and sex-differences in the development of spontaneous autoimmune diseases, important question still remains regarding the stability of XCI escape in immune cells and the underlying molecular mechanisms controlling XCI escape at single-cell resolution. In addition, the direct causal link between escape from $\mathrm{XCI}$, namely the additional expression of genes from the $\mathrm{Xi}$, and the greater susceptibility to develop autoimmune diseases remains to be demonstrated and will require the implementation of new genetic tools. Lastly, examination of the epigenetic and 3D-conformation landscape of the genomic regions of candidate escape genes should shed lights on the mechanisms controlling expression of these genes from the $\mathrm{Xi}$, and could open avenues for the development of novel therapeutics in autoimmune diseases associated with dosage imbalance of X-linked genes.

Author Contributions: All authors have made a substantial, direct, and intellectual contribution to the work and approved it for publication.

Funding: The authors would like to thank the French National Network for Rare Endocrine Diseases FIRENDO (www.firendo.fr) - supported by the Ministry of Health as part of the 3nd National Plan for Rare Diseases (2018-2022) — for providing financial support for the publication of this article.

Acknowledgments: The research carried out in the laboratory of JC Guéry benefits from the support of the Agence National de la Recherche (ANR), the French National Agency for Research on AIDS and Viral Hepatitis (ANRS), SIDACTION, Fondation pour la Recherche Médicale (DEQ20180339187), the CSL Behring Research Funds, the Arthritis Foundation, the ARSEP Foundation, the FOREUM Foundation and the Occitanie Region. Ali Youness receives study assistance from the Fondation des Treilles and from the "Association de la Charité des jeunes de Kafarsir (Liban).

Conflicts of Interest: The authors declare that the research was conducted in the absence of any commercial or financial relationships that could be construed as a potential conflict of interest.

$\begin{array}{ll}\text { Abbreviations } \\ \text { XCI } & \text { X chromosome inactivation } \\ \mathrm{Xa} & \text { active } \mathrm{X} \text { chromosome } \\ \mathrm{Xi} & \text { inactive } \mathrm{X} \text { chromosome } \\ \mathrm{SLE} & \text { systemic lupus erythematosus } \\ \mathrm{RA} & \text { rheumatoid arthritis } \\ \mathrm{MS} & \text { multiple sclerosis } \\ \text { IFN-I } & \text { Interferon type I } \\ \text { pDC } & \text { plasmacytoid dendritic cell } \\ \text { TLR } & \text { Toll-like receptor } \\ \text { IRF } & \text { interferon regulatory factor } \\ \text { EAE } & \text { experimental autoimmune encephalomyelitis } \\ \text { HIV } & \text { human immunodeficiency virus }\end{array}$

\section{References}

1. Laffont, S.; Guery, J.C. Deconstructing the sex bias in allergy and autoimmunity: From sex hormones and beyond. Adv. Immunol. 2019, 142, 35-64.

2. NIH Autoimmune Diseases Coordinating Committee (ADCC). Progress in Autoimmune Diseases Research: Report to Congress. $\mathrm{NIH}$ publication number $\mathrm{N}^{\circ}$ 05-5140 2005. Available online: https:/ /www.niaid.nih.gov/sites/default/files/adccfinal.pdf (accessed on 1 March 2005).

3. Billi, A.C.; Kahlenberg, J.M.; Gudjonsson, J.E. Sex bias in autoimmunity. Curr. Opin. Rheumatol. 2019, 31, 53-61. [CrossRef]

4. Fink, A.L.; Klein, S.L. The evolution of greater humoral immunity in females than males: Implications for vaccine efficacy. Curr. Opin. Physiol. 2018, 6, 16-20. [CrossRef]

5. Klein, S.L.; Flanagan, K.L. Sex differences in immune responses. Nat. Rev. Immunol. 2016, 16, 626-638. [CrossRef]

6. Zuk, M. The sicker sex. PLoS Pathog. 2009, 5, e1000267. [CrossRef] 
7. Bach, J.F. The hygiene hypothesis in autoimmunity: The role of pathogens and commensals. Nat. Rev. Immunol. 2018, 18, 105-120. [CrossRef]

8. Libert, C.; Dejager, L.; Pinheiro, I. The X chromosome in immune functions: When a chromosome makes the difference. Nat. Rev. Immunol. 2010, 10, 594-604. [CrossRef] [PubMed]

9. Smith-Bouvier, D.L.; Divekar, A.A.; Sasidhar, M.; Du, S.; Tiwari-Woodruff, S.K.; King, J.K.; Arnold, A.P.; Singh, R.R.; Voskuhl, R.R. A role for sex chromosome complement in the female bias in autoimmune disease. J. Exp. Med. 2008, 205, 1099-1108. [CrossRef] [PubMed]

10. Sasidhar, M.V.; Itoh, N.; Gold, S.M.; Lawson, G.W.; Voskuhl, R.R. The XX sex chromosome complement in mice is associated with increased spontaneous lupus compared with XY. Ann. Rheum. Dis. 2012, 71, 1418-1422. [CrossRef] [PubMed]

11. Scofield, R.H.; Bruner, G.R.; Namjou, B.; Kimberly, R.P.; Ramsey-Goldman, R.; Petri, M.; Reveille, J.D.; Alarcon, G.S.; Vila, L.M.; Reid, J.; et al. Klinefelter's syndrome (47,XXY) in male systemic lupus erythematosus patients: Support for the notion of a gene-dose effect from the X chromosome. Arthritis Rheumatol. 2008, 58, 2511-2517. [CrossRef] [PubMed]

12. Harris, V.M.; Sharma, R.; Cavett, J.; Kurien, B.T.; Liu, K.; Koelsch, K.A.; Rasmussen, A.; Radfar, L.; Lewis, D.; Stone, D.U.; et al Klinefelter's syndrome (47,XXY) is in excess among men with Sjögren's syndrome. Clin. Immunol. 2016, 168, 25-29. [CrossRef] [PubMed]

13. Fang, H.; Disteche, C.M.; Berletch, J.B. X Inactivation and Escape: Epigenetic and Structural Features. Front. Cell Dev. Biol. 2019, 7, 219. [CrossRef]

14. Graves, J.A.; Wakefield, M.J.; Toder, R. The origin and evolution of the pseudoautosomal regions of human sex chromosomes. Hum. Mol. Genet. 1998, 7, 1991-1996. [CrossRef] [PubMed]

15. Fish, E.N. The X-files in immunity: Sex-based differences predispose immune responses. Nat. Rev. Immunol. 2008, 8, 737-744. [CrossRef] [PubMed]

16. Pinheiro, I.; Dejager, L.; Libert, C. X-chromosome-located microRNAs in immunity: Might they explain male/female differences? The $\mathrm{X}$ chromosome-genomic context may affect $\mathrm{X}$-located miRNAs and downstream signaling, thereby contributing to the enhanced immune response of females. Bioessays 2011, 33, 791-802. [CrossRef] [PubMed]

17. Barreiro, L.B.; Ben-Ali, M.; Quach, H.; Laval, G.; Patin, E.; Pickrell, J.K.; Bouchier, C.; Tichit, M.; Neyrolles, O.; Gicquel, B.; et al. Evolutionary dynamics of human Toll-like receptors and their different contributions to host defense. PLoS Genet. 2009, 5, e1000562. [CrossRef] [PubMed]

18. van der Made, C.I.; Simons, A.; Schuurs-Hoeijmakers, J.; van den Heuvel, G.; Mantere, T.; Kersten, S.; van Deuren, R.C.; Steehouwer, M.; van Reijmersdal, S.V.; Jaeger, M.; et al. Presence of Genetic Variants among Young Men With Severe COVID-19. JAMA 2020, 324, 663-673. [CrossRef]

19. Carrel, L.; Willard, H.F. X-inactivation profile reveals extensive variability in X-linked gene expression in females. Nature 2005, 434, 400-404. [CrossRef]

20. Tukiainen, T.; Villani, A.C.; Yen, A.; Rivas, M.A.; Marshall, J.L.; Satija, R.; Aguirre, M.; Gauthier, L.; Fleharty, M.; Kirby, A.; et al. Landscape of $X$ chromosome inactivation across human tissues. Nature 2017, 550, 244-248. [CrossRef]

21. Wang, J.; Syrett, C.M.; Kramer, M.C.; Basu, A.; Atchison, M.L.; Anguera, M.C. Unusual maintenance of X chromosome inactivation predisposes female lymphocytes for increased expression from the inactive X. Proc. Natl. Acad. Sci. USA 2016, 113, E2029-E2038. [CrossRef]

22. Hagen, S.H.; Henseling, F.; Hennesen, J.; Savel, H.; Delahaye, S.; Richert, L.; Ziegler, S.M.; Altfeld, M. Heterogeneous Escape from $X$ Chromosome Inactivation Results in Sex Differences in Type I IFN Responses at the Single Human pDC Level. Cell Rep. 2020, 33, 108485. [CrossRef] [PubMed]

23. Souyris, M.; Cenac, C.; Azar, P.; Daviaud, D.; Canivet, A.; Grunenwald, S.; Pienkowski, C.; Chaumeil, J.; Mejia, J.E.; Guery, J.C. TLR7 escapes X chromosome inactivation in immune cells. Sci. Immunol. 2018, 3, eaap8855. [CrossRef] [PubMed]

24. Greenfield, A.; Carrel, L.; Pennisi, D.; Philippe, C.; Quaderi, N.; Siggers, P.; Steiner, K.; Tam, P.P.; Monaco, A.P.; Willard, H.F.; et al. The UTX gene escapes X inactivation in mice and humans. Hum. Mol. Genet. 1998, 7, 737-742. [CrossRef] [PubMed]

25. Heinz, L.X.; Lee, J.; Kapoor, U.; Kartnig, F.; Sedlyarov, V.; Papakostas, K.; Cesar-Razquin, A.; Essletzbichler, P.; Goldmann, U.; Stefanovic, A.; et al. TASL is the SLC15A4-associated adaptor for IRF5 activation by TLR7-9. Nature 2020, 581, 316-322. [CrossRef] [PubMed]

26. Souyris, M.; Mejia, J.E.; Chaumeil, J.; Guery, J.C. Female predisposition to TLR7-driven autoimmunity: Gene dosage and the escape from $X$ chromosome inactivation. Semin. Immunopathol. 2019, 41, 153-164. [CrossRef]

27. de Marcken, M.; Dhaliwal, K.; Danielsen, A.C.; Gautron, A.S.; Dominguez-Villar, M. TLR7 and TLR8 activate distinct pathways in monocytes during RNA virus infection. Sci. Signal. 2019, 12, eaaw1347. [CrossRef]

28. Ah Kioon, M.D.; Tripodo, C.; Fernandez, D.; Kirou, K.A.; Spiera, R.F.; Crow, M.K.; Gordon, J.K.; Barrat, F.J. Plasmacytoid dendritic cells promote systemic sclerosis with a key role for TLR8. Sci. Transl. Med. 2018, 10, eaam8458. [CrossRef]

29. Pisitkun, P.; Deane, J.A.; Difilippantonio, M.J.; Tarasenko, T.; Satterthwaite, A.B.; Bolland, S. Autoreactive B cell responses to RNA-related antigens due to TLR7 gene duplication. Science 2006, 312, 1669-1672. [CrossRef]

30. Deane, J.A.; Pisitkun, P.; Barrett, R.S.; Feigenbaum, L.; Town, T.; Ward, J.M.; Flavell, R.A.; Bolland, S. Control of toll-like receptor 7 expression is essential to restrict autoimmunity and dendritic cell proliferation. Immunity 2007, 27, 801-810. [CrossRef]

31. Guiducci, C.; Gong, M.; Cepika, A.M.; Xu, Z.; Tripodo, C.; Bennett, L.; Crain, C.; Quartier, P.; Cush, J.J.; Pascual, V.; et al. RNA recognition by human TLR8 can lead to autoimmune inflammation. J. Exp. Med. 2013, 210, 2903-2919. [CrossRef] 
32. Christensen, S.R.; Shupe, J.; Nickerson, K.; Kashgarian, M.; Flavell, R.A.; Shlomchik, M.J. Toll-like receptor 7 and TLR9 dictate autoantibody specificity and have opposing inflammatory and regulatory roles in a murine model of lupus. Immunity 2006, 25, 417-428. [CrossRef] [PubMed]

33. Theofilopoulos, A.N.; Kono, D.H.; Baccala, R. The multiple pathways to autoimmunity. Nat. Immunol 2017, 18, 716-724. [CrossRef] [PubMed]

34. Azar, P.; Mejia, J.E.; Cenac, C.; Shaiykova, A.; Youness, A.; Laffont, S.; Essat, A.; Izopet, J.; Passaes, C.; Muller-Trutwin, M.; et al. TLR7 dosage polymorphism shapes interferogenesis and HIV-1 acute viremia in women. JCI Insight 2020, 5, e136047. [CrossRef] [PubMed]

35. Cotton, A.M.; Lam, L.; Affleck, J.G.; Wilson, I.M.; Peñaherrera, M.S.; McFadden, D.E.; Kobor, M.S.; Lam, W.L.; Robinson, W.P.; Brown, C.J. Chromosome-wide DNA methylation analysis predicts human tissue-specific X inactivation. Hum. Genet. 2011, 130, 187-201. [CrossRef] [PubMed]

36. Odhams, C.A.; Roberts, A.L.; Vester, S.K.; Duarte, C.S.T.; Beales, C.T.; Clarke, A.J.; Lindinger, S.; Daffern, S.J.; Zito, A.; Chen, L.; et al. Interferon inducible X-linked gene CXorf21 may contribute to sexual dimorphism in Systemic Lupus Erythematosus. Nat. Commun. 2019, 10, 2164. [CrossRef]

37. Mackay, M.; Oswald, M.; Sanchez-Guerrero, J.; Lichauco, J.; Aranow, C.; Kotkin, S.; Korsunsky, I.; Gregersen, P.K.; Diamond, B. Molecular signatures in systemic lupus erythematosus: Distinction between disease flare and infection. Lupus Sci. Med. 2016, 3, e000159. [CrossRef]

38. Oghumu, S.; Varikuti, S.; Stock, J.C.; Volpedo, G.; Saljoughian, N.; Terrazas, C.A.; Satoskar, A.R. Cutting Edge: CXCR3 Escapes X Chromosome Inactivation in T Cells during Infection: Potential Implications for Sex Differences in Immune Responses. J. Immunol. 2019, 203, 789-794. [CrossRef]

39. Le Coz, C.; Trofa, M.; Syrett, C.M.; Martin, A.; Jyonouchi, H.; Jyonouchi, S.; Anguera, M.C.; Romberg, N. CD40LG duplicationassociated autoimmune disease is silenced by nonrandom X-chromosome inactivation. J. Allergy Clin. Immunol. 2018, 141, 23082311.e7. [CrossRef]

40. Berletch, J.B.; Ma, W.; Yang, F.; Shendure, J.; Noble, W.S.; Disteche, C.M.; Deng, X. Escape from X inactivation varies in mouse tissues. PLoS Genet. 2015, 11, e1005079. [CrossRef]

41. Itoh, Y.; Golden, L.C.; Itoh, N.; Matsukawa, M.A.; Ren, E.; Tse, V.; Arnold, A.P.; Voskuhl, R.R. The X-linked histone demethylase Kdm6a in CD4+ T lymphocytes modulates autoimmunity. J. Clin. Investig. 2019, 130, 3852-3863. [CrossRef]

42. Dunford, A.; Weinstock, D.M.; Savova, V.; Schumacher, S.E.; Cleary, J.P.; Yoda, A.; Sullivan, T.J.; Hess, J.M.; Gimelbrant, A.A.; Beroukhim, R.; et al. Tumor-suppressor genes that escape from X-inactivation contribute to cancer sex bias. Nat. Genet. 2017, 49, 10-16. [CrossRef] [PubMed]

43. Brown, C.J.; Willard, H.F. The human X-inactivation centre is not required for maintenance of X-chromosome inactivation. Nature 1994, 368, 154-156. [CrossRef] [PubMed]

44. Csankovszki, G.; Nagy, A.; Jaenisch, R. Synergism of Xist RNA, DNA methylation, and histone hypoacetylation in maintaining X chromosome inactivation. J. Cell Biol. 2001, 153, 773-784. [CrossRef] [PubMed]

45. Savarese, F.; Flahndorfer, K.; Jaenisch, R.; Busslinger, M.; Wutz, A. Hematopoietic precursor cells transiently reestablish permissiveness for X inactivation. Mol. Cell Biol. 2006, 26, 7167-7177. [CrossRef] [PubMed]

46. Syrett, C.M.; Sindhava, V.; Hodawadekar, S.; Myles, A.; Liang, G.; Zhang, Y.; Nandi, S.; Cancro, M.; Atchison, M.; Anguera, M.C. Loss of Xist RNA from the inactive $\mathrm{X}$ during $\mathrm{B}$ cell development is restored in a dynamic $\mathrm{YY} 1$-dependent two-step process in activated B cells. PLoS Genet. 2017, 13, e1007050. [CrossRef]

47. Syrett, C.M.; Paneru, B.; Sandoval-Heglund, D.; Wang, J.; Banerjee, S.; Sindhava, V.; Behrens, E.M.; Atchison, M.; Anguera, M.C. Altered X-chromosome inactivation in T cells may promote sex-biased autoimmune diseases. JCI Insight 2019, 4, e126751. [CrossRef]

48. Syrett, C.M.; Sierra, I.; Beethem, Z.T.; Dubin, A.H.; Anguera, M.C. Loss of epigenetic modifications on the inactive X chromosome and sex-biased gene expression profiles in B cells from NZB/W F1 mice with lupus-like disease. J. Autoimmun. 2019, $107,102357$. [CrossRef]

49. Adrianse, R.L.; Smith, K.; Gatbonton-Schwager, T.; Sripathy, S.P.; Lao, U.; Foss, E.J.; Boers, R.G.; Boers, J.B.; Gribnau, J.; Bedalov, A. Perturbed maintenance of transcriptional repression on the inactive X-chromosome in the mouse brain after Xist deletion. Epigenetics Chromatin 2018, 11, 50. [CrossRef]

50. Ober, C.; Loisel, D.A.; Gilad, Y. Sex-specific genetic architecture of human disease. Nat. Rev. Genet. 2008, 9, 911-922. [CrossRef]

51. Laffont, S.; Rouquie, N.; Azar, P.; Seillet, C.; Plumas, J.; Aspord, C.; Guery, J.C. X-Chromosome complement and estrogen receptor signaling independently contribute to the enhanced TLR7-mediated IFN-alpha production of plasmacytoid dendritic cells from women. J. Immunol. 2014, 193, 5444-5452. [CrossRef]

52. dos Santos, B.P.; Valverde, J.V.; Rohr, P.; Monticielo, O.A.; Brenol, J.C.; Xavier, R.M.; Chies, J.A. TLR7/8/9 polymorphisms and their associations in systemic lupus erythematosus patients from southern Brazil. Lupus 2012, 21, 302-309. [CrossRef] [PubMed]

53. Pavlovic, M.; Kats, A.; Cavallo, M.; Shoenfeld, Y. Clinical and molecular evidence for association of SLE with parvovirus B19. Lupus 2010, 19, 783-792. [CrossRef] [PubMed] 
54. Gonzalez-Quintial, R.; Nguyen, A.; Kono, D.H.; Oldstone, M.B.A.; Theofilopoulos, A.N.; Baccala, R. Lupus acceleration by a MAVS-activating RNA virus requires endosomal TLR signaling and host genetic predisposition. PLoS ONE 2018, 13, e0203118. [CrossRef] [PubMed]

55. Griesbeck, M.; Ziegler, S.; Laffont, S.; Smith, N.; Chauveau, L.; Tomezsko, P.; Sharei, A.; Kourjian, G.; Porichis, F.; Hart, M.; et al. Sex Differences in Plasmacytoid Dendritic Cell Levels of IRF5 Drive Higher IFN-alpha Production in Women. J. Immunol. 2015, 195, 5327-5336. [CrossRef] 